Original Article

\title{
DEVELOPMENT AND VALIDATION OF UV-SPECTROPHOTOMETRIC METHOD FOR ESTIMATION OF HYDROQUINONE IN BULK, MARKETED CREAM AND PREAPARED NLC FORMULATION
}

\author{
SUKHJINDER KAUR ${ }^{1,2}$, TARANJIT KAUR ${ }^{1,2}$, GURDEEP KAUR ${ }^{1,2}$, SHIVANI VERMA ${ }^{1,2 *}$
}

${ }^{1}$ Department of Pharmaceutics, Rayat Bahra Institute of Pharmacy, Education City, Hoshiarpur, Punjab 146001, India, ${ }^{2}$ I. K. Gujral Punjab Technical University, Jalandhar, Punjab 144601, India

Email: vermashivani.10@gmail.com

Received: 03 Jun 2017, Revised and Accepted: 22 Aug 2017

\section{ABSTRACT}

Objective: The aim of the present work was to develop a simple, rapid, accurate and economical UV-visible spectrophotometric method for the determination of hydroquinone (HQ) in its pure form, marketed formulation as well as in the prepared nanostructured lipid carrier (NLC) systems and to validate the developed method.

Methods: HQ was estimated at UV maxima of $289.6 \mathrm{~nm}$ in pH 5.5 phosphate buffer using UV-Visible double beam spectrophotometer. Following the guidelines of the International Conference on Harmonization (ICH), the method was validated for various analytical parameters like linearity, precision, and accuracy robustness, ruggedness, limit of detection, quantification limit, and formulation analysis.

Results: The obtained results of the analysis were validated statistically. Recovery studies were performed to confirm the accuracy of the proposed method. In the developed method, linearity over the concentration range of $5-40 \mu \mathrm{g} / \mathrm{ml}$ of HQ was observed with the correlation coefficient of 0.998 and found in good agreement with Beer Lambert's law. The precision (intra-day and inter-day) of the method was found within official RCD limits $(\mathrm{RSD}<2 \%)$.

Conclusion: The sensitivity of the method was assessed by determining the limit of detection and limit of quantification. It could be concluded from the results obtained that the purposed method for estimation of $\mathrm{HQ}$ in pure form, in the marketed ointment and in the prepared NLC-formulation was simple, rapid, accurate, precise and economical. It can be used successfully in the quality control of pharmaceutical formulations and for the routine laboratory analysis.

Keywords: Hydroquinone, UV Spectrophotometer, Nanostructured lipid carriers, Validation

(c) 2017 The Authors. Published by Innovare Academic Sciences Pvt Ltd. This is an open access article under the CC BY license (http://creativecommons.org/licenses/by/4.0/) DOI: http://dx.doi.org/10.22159/ijap.2017v9i5.20467

\section{INTRODUCTION}

Hydroquinone is chemically (1, 4-dihydroxybenzene) phenolic compound (fig. 1) having chemical formula $\mathrm{C}_{6} \mathrm{H}_{4}(\mathrm{OH})_{2}$. It is a watersoluble reducing agent which is used widely in topical skin creams. It acts as a di-pigmenting agent by inhibiting melanogenesis $[1,2]$. It is useful in the treatment of dyschromias (melasma), contact vitiligo, post inflammatory hyper pigmentation (PIH), seborrheic dermatitis and exogenous ochronosisetc [3].

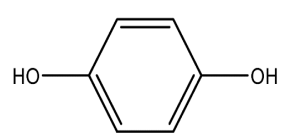

Fig. 1: Chemical structure of hydroquinone

HQ mainly affects melanocytes in the process of melanogenesis and treated as the gold standard therapy for PIH. It acts by causing reversible inhibition of tyrosinase enzymes and damage melanosomes and melanocytes, thus it lowers down the melanin content in the new keratinocytes formed. It is commonly used at concentrations of $2-4 \%$ [4]. It is safely combined with retinoids and steroids in kligman's regimen $(5 \%$ hydroquinone, $0.1 \%$ dexamethasone, $0.1 \%$ tretinoin) used to treat hyper pigmentation. The commercially available HQ cream $4 \%$ is a whitish cream and is indicated for acute hyperpigmentation resulting due to acne scars, $\mathrm{PIH}$, melasma, etc. HQ, when used in concentrations greater than $4 \%$, can lead to skin irritation, skin redness, and dermatitis, etc.[5]. Topical drugs, when delivered through conventional formulations, faces the major hurdle of crossing the stratum corneum layer which act as a barrier against skin permeation. So, these drugs are formulated in lipid carrier systems like liposomes, niosomes, solid lipid nanoparticles (SLN), nano lipid carriers (NLC), ethosomes, transferosomes which increase skin permeation and further improves the bioavailability of active molecule [6-9]. In the present study, NLC formulation of $\mathrm{HQ}$ was prepared that provides effective treatment in hyper pigmentation and melasma by passing the major obstacle in skin permeation. A detailed literature survey regarding existing methods of analysis like high-performance liquid chromatography (HPLC) [10], thin layer chromatography (TLC) [11], micellar electrokinetic chromatography (MEKC) [12], and capillary electrochromatography (CEC) techniques [13] in various biological matrices revealed that these methods are expensive, more sophisticated and involves extensive skills, thus there is need to develop simple spectrophotometric method for the estimation of Hydroquinone in various dosage forms. There is one reported UV spectrophotometric method for the estimation of hydroquinone individually in liposomes using methanol [14] and other UV spectrophotometric method for the simultaneous estimation of tazarotene and hydroquinone in gel preparation [15]. The present study focus on the development of more suitable, cheap, easy and validated UV spectrophotometric method for determination of HQ in different dosage forms that eliminate the use of toxic organic solvents and provides the eco-friendly study. In this context, UVspectrophotometry is the best-reported method. So the principle objective of the study was to develop UV spectrophotometric method with good linear range and sensitivity for the assay of hydroquinone in the marketed cream and NLC.

\section{MATERIALS AND METHODS}

Material

A standard sample of $\mathrm{HQ}$ was obtained as a gratis sample from Chemitt India Pvt. Ltd. The marketed hydroquinone cream USP 
containing $4 \% \mathrm{w} / \mathrm{w}$ of hydroquinone manufactured by Abbott Healthcare Pvt. Ltd, was procured from local market.

\section{For preparation of HQ loaded NLC}

Compritol 888 ATO and TPGS 1000 was obtained as gift sample from Stearinerie Dubois Fils, Ciron, France and Isochem S. A. Gennevilliers, France respectively. Pure almond oil was gifted by Yash Exports. Transcutol was obtained from $\mathrm{CDH}$ laboratories. All the other chemicals used in the study were of analytical grades.

\section{Instrumentation}

\section{For method validation}

A double beam Systronics UV-Visible spectrophotometer, model UV2201 (India) with a spectral bandwidth of $1 \mathrm{~nm}$, wavelength accuracy of $\pm 0.5 \mathrm{~nm}$ and a pair of $1 \mathrm{~cm}$ quartz cells were used to measure the absorbance of the resulting solutions.

\section{For the preparation of NLC of HQ}

Homogenizer, RQT-127A remimotors, Vasai, India, magnetic stirrer LE-17 spruce enterprises, Ambala (Haryana), bath sonicator, Apl Indian Machine tools, Delhi were used to prepare NLC of HQ

\section{Preparation of hydroquinone-loaded NLC}

An accurately weighed $100 \mathrm{mg}$ of drug was added in a molten solution of solid lipid (compritol 888 ATO) and liquid lipid (almond oil) at the melting temperature $\left(72^{\circ} \mathrm{C}\right)$ of solid lipid. The surfactant solution was prepared separately by adding TPGS 1000 to the $50 \mathrm{ml}$ of the distilled water containing transcutol as co-surfactant at bath sonicator for about 15 min which was later heated to the same temperature as melted lipid. A weighed amount of drug was dissolved in the $10 \mathrm{ml}$ of heated surfactant solution and added drop- wise to the lipid melt under constant temperature and stirring conditions. Further, the entire surfactant solution was added and stirred continuously for about half hour. The mixture was then transferred into high shear homogenizer and stirred for about 20 min at the speed of $12,000 \mathrm{rpm}$. The final formulation was collected and cooled down in the beaker $[16,17]$.

\section{Analytical method development}

\section{Selection of solvent}

A suitable solvent is selected on the basis of stability and solubility of the drug in solvent system as well as extraction of the drug from its formulation [18]. HQ pure form, HQ NLC formulation and its marketed formulation can freely solubilize in $5.5 \mathrm{pH}$ phosphate buffer which also resembles to the $\mathrm{pH}$ of the skin.

Hence $5.5 \mathrm{pH}$ phosphate buffer was selected as a solvent for UV spectrophotometric determination.

\section{Preparation of standard stock solution $(1000 \mu \mathrm{g} / \mathrm{ml})$}

Accurately weighed quantity of $100 \mathrm{mg}$ of $\mathrm{HQ}$ was transferred into $100 \mathrm{ml}$ volumetric flask which was dissolved and diluted up to the mark with $5.5 \mathrm{pH}$ phosphate buffer [19]. The solution was sonicated on bath sonicator to get a clear standard stock solution $(1000 \mu \mathrm{g} / \mathrm{ml})$.

\section{Determination of $\lambda$ max}

The standard stock solution of $\mathrm{HQ}$ having the concentration $1000 \mu \mathrm{g} / \mathrm{ml}$ was further diluted to $100 \mu \mathrm{g} / \mathrm{ml}$ with $5.5 \mathrm{pH}$ phosphate buffer. The absorbance of the resultant solution was scanned in the UV spectrophotometer ranging from $200-400 \mathrm{~nm}$ $[20,21]$. The plot shows the maximum absorbance at $289.6 \mathrm{~nm}$ as shown below in fig. 2 .

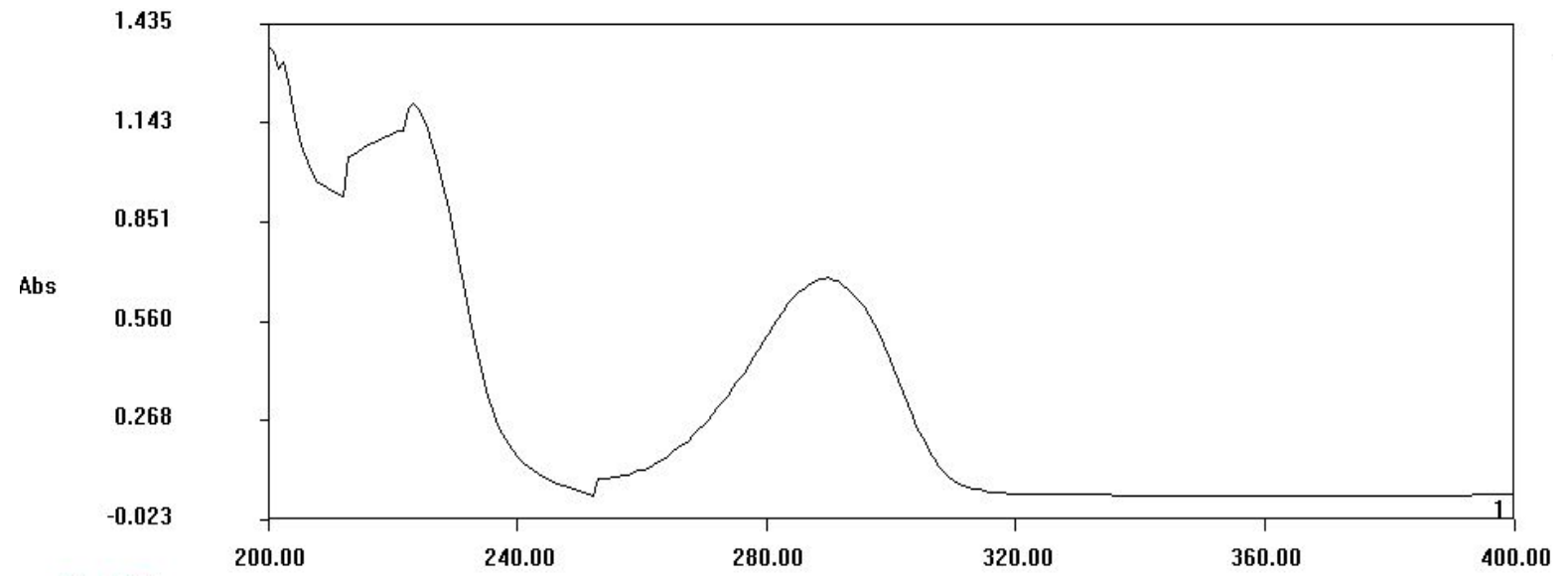

Fig. 2: UV visible spectrum scan of HQ showing $\lambda$ maxat $289.6 \mathrm{~nm}$

\section{Preparation of standard sample solution (pure drug)}

For the spectrophotometric analysis, stock solution of $\mathrm{HQ}$ was prepared by dissolving $100 \mathrm{mg}$ of $\mathrm{HQ}$ in $100 \mathrm{ml}$ of $5.5 \mathrm{pH}$ phosphate buffer to obtain a final concentration of $1000 \mu \mathrm{g} / \mathrm{ml}$. Further, the mixture was sonicated for 1 minute. The solution was then filtered $[22,23]$. From this stock solution, $10 \mathrm{ml}$ of the solution was taken and transferred to $100 \mathrm{ml}$ volumetric flask and diluted with $5.5 \mathrm{pH}$ phosphate buffer to get the solution with concentration of $100 \mu \mathrm{g} / \mathrm{ml}$. From this solution, serial dilutions were made to prepare sample solutions of concentrations ranging from $5-40 \mu \mathrm{g} / \mathrm{ml}$ and were analyzed at $289.6 \mathrm{~nm}$.

\section{Preparation of test sample solution (Marketed formulation)}

An amount equivalent to $100 \mathrm{mg}$ of $\mathrm{HQ}$ from commercially available, MELALITE ${ }^{\circledR}$ FORTE CREAM $4 \%$ USP (ABBOTT
HEALTHCARE) was weighed accurately and transferred into 100 ml volumetric flask. $20 \mathrm{ml}$ of $5.5 \mathrm{pH}$ phosphate buffer was added and mixed thoroughly and the volume was made up to $100 \mathrm{ml}$ with the same solvent, the mixture was then sonicated for 1 minute and filtered through whatmann filter paper (no. 41). From this stock solution, $10 \mathrm{ml}$ of solution was taken and transferred to $100 \mathrm{ml}$ volumetric flask and diluted with $5.5 \mathrm{pH}$ phosphate buffer. From this solution, dilutions were prepared and analyzed at $289.6 \mathrm{~nm}$.

\section{Preparation of test sample solution (Prepared NLC formulation)}

An accurate volume of an amount equivalent to $100 \mathrm{mg}$ of HQ from prepared NLC formulation was taken accurately and mixed with 25 $\mathrm{ml}$ of $5.5 \mathrm{pH}$ phosphate buffer and volume was made up to $100 \mathrm{ml}$ with buffer, the mixture was sonicated for 1 minute and finally filtered through Whatman filter paper (no. 41) [24]. From this stock 
solution, $10 \mathrm{ml}$ of solution was taken and transferred to $100 \mathrm{ml}$ volumetric flask and diluted with $5.5 \mathrm{pH}$ phosphate buffer to $100 \mathrm{ml}$. From this solution, various dilutions were prepared and analyzed at $289.6 \mathrm{~nm}$

\section{Validation of UV spectrophotometric method}

\section{Linearity and range}

From the stock solution, aliquots of concentrations ranging from $5-40 \mu \mathrm{g} / \mathrm{ml}$ were prepared in triplicate. Absorbance values of these solutions were measured at $\lambda \max 289.6 \mathrm{~nm}$. The calibration curve was plotted between concentrations of HQ and respectively measured absorbances. Linearity was calculated by least square regression method [25]. The stability of the drug in the solvent system and during the actual analysis was also investigated.

\section{Accuracy}

Accuracy and precision of the method were studied with the help of percent recovery, standard deviation (SD), and percent relative standard deviation (RSD) by using standard addition method. Accuracy is the percentage of analyte recovered by an assay from the known added amount. Three levels of standard drug $(75 \%, 100 \%$, and $125 \%$ ) from $\mathrm{HQ}$ sample solution were spiked individually with the 10 $\mu \mathrm{g} / \mathrm{ml}$ equivalent of HQ MELALITE ${ }^{\circledR}$ forte cream $4 \%$ USP and $10 \mu \mathrm{g} / \mathrm{ml}$ equivalent concentration of $\mathrm{HQ}$ from prepared HQ loaded NLC formulation [26-27]. All the readings were taken in triplicate at all levels.

\section{Precision}

Precision is the degree of repeatability of an analytical method under normal operational conditions. The precision of the method was determined by repeatability (intraday) and intermediate precision (inter-day) and reported as RSD \% for a statistically significant number of replicate measurements [28]. Samples at different concentrations were analyzed in three replicates during the same day (intraday precision) and three consecutive days (interday precision). The results obtained were tabulated along with standard error and $95 \%$ confidence interval.

\section{Limit of detection (LOD) and limit of quantitation (LOQ)}

LOD represents the lowest amount of an analyte in a sample that an analytical process can differentiate from other levels. The LOD and LOQ were determined by using the standard deviation of the response and slope of the corresponding calibration curve. LOD was determined by using following equation

$$
\mathrm{LOD}=3.3 * \sigma / \mathrm{s}
$$

Where, $\sigma=$ the standard deviation of $y$-intercepts of regression lines $\mathrm{S}=$ the slope of the calibration curve [29].

LOQ represents the lowest concentration of an analyte in a sample which can be quantitatively determined with an acceptable accuracy, precision and variability. LOQ was calculated by using the following relation

$$
\mathrm{LOQ}=10 * \sigma / \mathrm{s}
$$

\section{Repeatability}

Repeatability was determined by analyzing $20 \mu \mathrm{g} / \mathrm{ml}$ concentration of $\mathrm{HQ}$ solution for six times. From the resulting absorbance, the standard deviation and relative standard deviation were calculated [30].

\section{Ruggedness}

The ruggedness of the proposed method was determined for 20 $\mu \mathrm{g} / \mathrm{ml}$ concentration of $\mathrm{HQ}$ by analysis of aliquots from a homogenous slot by two analysts using same operational and environmental conditions [30].

\section{Robustness}

Robustness was studied by evaluating the influence of small but deliberate variations in the experimental condition like changing the wavelength (287.6 and $291.6 \mathrm{~nm}$ ) for the analytical performance [31].

\section{Forced degradation study}

A $2 \mathrm{ml}$ aliquot of standard stock solution of HQ $(1 \mathrm{mg} / \mathrm{ml})$ was taken in four replicates in a volumetric flask $(100 \mathrm{ml})$ and mixed with $10 \mathrm{ml}$ of $0.1 \mathrm{~N} \mathrm{HCl}$ (acid hydrolysis) or $0.1 \mathrm{~N} \mathrm{NaOH}$ (alkaline hydrolysis) or $5 \% \mathrm{H}_{2} \mathrm{O}_{2}$ (oxidative degradation) and set aside for $1 \mathrm{~h}$ at room temperature.

The solution was diluted up to mark with distilled water. For photolytic degradation, a solution of drug $(20 \mu \mathrm{g} / \mathrm{ml})$ was prepared as per the procedure under construction of the calibration graph and was exposed to UV radiation of wavelength $289.6 \mathrm{~nm}$ and of 1.4 flux intensity for $24 \mathrm{~h}$ in a UV chamber. For thermal degradation solid drug was kept in an oven at $100^{\circ} \mathrm{C}$ for $24 \mathrm{~h} \mathrm{[32].}$

After cooling to room temperature, $20 \mu \mathrm{g} / \mathrm{ml}$ concentrated solution of drug was prepared by above said method. Finally, absorbance of all the solutions as the result of acidic and alkaline hydrolysis, oxidative, photolytic, and thermal degradation were measured at $289.6 \mathrm{~nm}$ against their solvent respectively as blank in each case [33].

\section{RESULTS AND DISCUSSION}

\section{Linearity and range}

It was found that the selected drug shows linearity between the range of $5-40 \mu \mathrm{g} / \mathrm{ml}$. Linearity range is presented in table 1 . The regression coefficient was found to be 0.998 , which meet the method validation, acceptance criteria and hence the method is said to be linear in the range of $5-40 \mu \mathrm{g} / \mathrm{ml}$ as shown below in fig. 3 .

The calibration curve shows that the drug obeys Beer's law limit within the concentration range. Furthermore, the overlay spectra of $\mathrm{HQ}$ in $5.5 \mathrm{pH}$ phosphate buffer support the linearity results observed in the standard curve as in fig. 3 .

Table 1: Calibration data of HQ by UV-spectroscopy

\begin{tabular}{lll}
\hline S. No. & Concentration $(\boldsymbol{\mu g} / \mathbf{m l})$ & Absorbance* $(\mathbf{n m})$ \\
\hline 1. & 5 & $0.086 \pm 0.003$ \\
2. & 10 & $0.197 \pm 0.021$ \\
3. & 15 & $0.318 \pm 0.002$ \\
4. & 20 & $0.428 \pm 0.004$ \\
5. & 25 & $0.535 \pm 0.001$ \\
6. & 30 & $0.655 \pm 0.003$ \\
7. & 35 & $0.764 \pm 0.002$ \\
8. & 40 & $0.867 \pm 0.014$ \\
\hline
\end{tabular}

*Average of three determinations. 


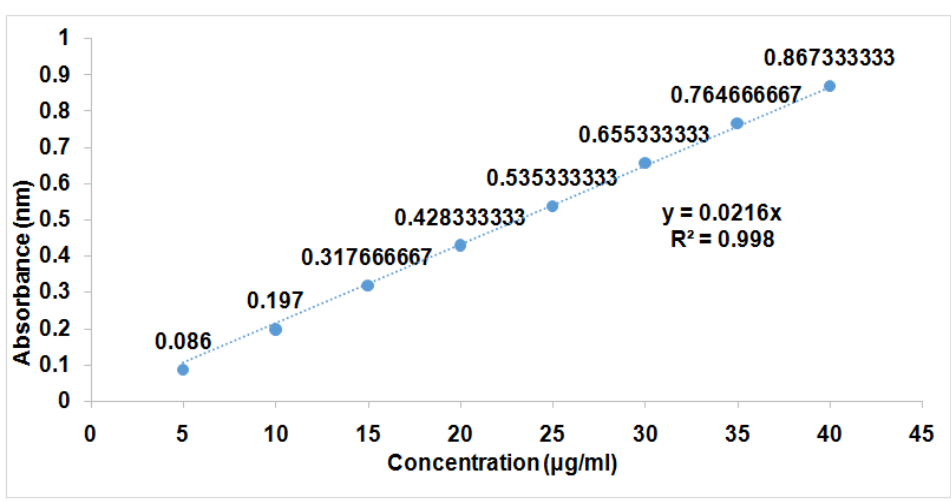

Fig. 3: Calibration curve of hydroquinone

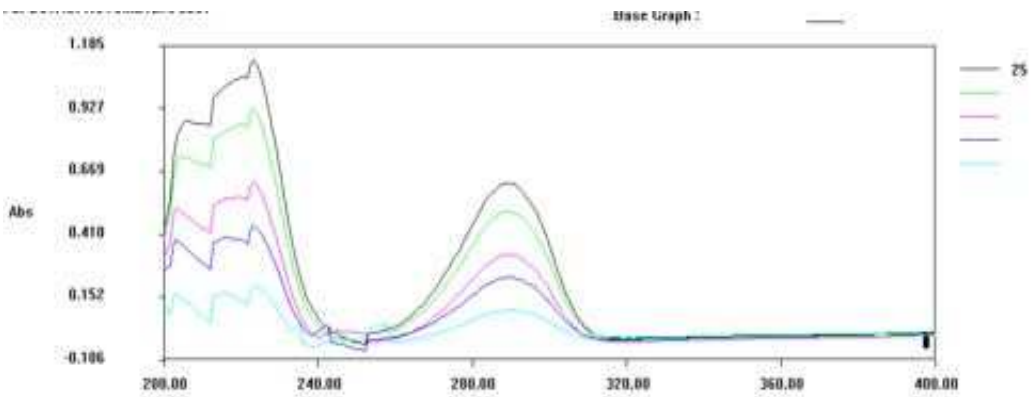

Fig. 4: Overlay spectra of $\mathrm{HQ}(\lambda \max 289.6)$ with concentration range from $5-25 \mu \mathrm{g} / \mathrm{ml}$

\section{Accuracy of marketed and prepared NLC-formulation}

Solutions were prepared in triplicate at levels $75 \%, 100 \%$ and $125 \%$ of drug concentration to the pre-analyzed HQ standard samples and the percent recovery values were calculated. The recovery results showed that the proposed method has an acceptable level of accuracy for HQ $(75 \%-125 \%$ of marketed formulation concentration) in the range of $99 \%-100 \%$.

Commercially available cream of HQ MELALITE ${ }^{\circledR}$ forte cream $4 \%$ USP (ABBOTT HEALTHCARE) and the prepared NLC formulation were selected for the estimation of total content by the proposed method. The acceptable level of HQ in 75\%-125\% of test concentration of prepared NLC-formulation was from $96-98 \%$.

Thus, the study indicates the absence of interaction between the drug and pharmaceutical additives and excipients. The results for both are shown in table 2 and 3, respectively. The differences between the assays obtained from the nine determinations ( 3 conc/3 replicates) are within the limits for both of marketed cream and prepared NLC. The $\%$ RSD acceptance criterion is $2 \%$.

Table 2: Results of recovery studies for marketed cream

\begin{tabular}{lllll}
\hline Recovery level & Initial conc. $(\boldsymbol{\mu g} / \mathbf{m l})$ & Conc. of standard drug added $(\boldsymbol{\mu g} / \mathbf{m l})$ & Abs. Mean* & \% recovery \pm SD \\
\hline $75 \%$ & 10 & 5 & 0.108 & $99.69 \pm 0.48$ \\
$100 \%$ & 10 & 10 & 0.217 & $100.77 \pm 0.32$ \\
$125 \%$ & 10 & 15 & 0.323 & $99.69 \pm 0.12$ \\
\hline
\end{tabular}

*Average of three concentration

Table 3: Result of recovery analysis of HQ NLC-formulation

\begin{tabular}{lllll}
\hline Recovery level & Conc. of drug from formulation $(\boldsymbol{\mu g} / \mathbf{m l})$ & Conc. of standard drug added $(\boldsymbol{\mu g} / \mathbf{m l})$ & Abs. mean* & \% recovery \pm SD \\
\hline $75 \%$ & 10 & 5 & 4.846 & $96.91 \pm 0.39$ \\
$100 \%$ & 10 & 10 & 9.985 & $99.85 \pm 0.63$ \\
$125 \%$ & 10 & 15 & 14.830 & $98.87 \pm 0.02$ \\
\hline
\end{tabular}

*Average of three concentration

\section{Precision}

The intraday and interday precisions were calculated by observing absorbance at three different time points in a day and for the three consecutive days. The absorbance result mean, SD and \% RSD was calculated and shown in table 5 and 6.
The acceptable limit for intraday variation should be within $1 \%$ and for inter-day variation should be within $2 \%$, and the results were found to be in range. Precision results thus indicate that the validation method used is reliable and repeatable. So, it can be successfully used for determination of drug in various different pharmaceutical dosage forms. 
Table 5: Intra-day precision data and statistical results

\begin{tabular}{|c|c|c|c|c|c|c|}
\hline $\begin{array}{l}\text { Concentration taken } \\
(\mu \mathrm{g} / \mathrm{ml})\end{array}$ & $\begin{array}{l}\text { Mean conc. found at } 10 \\
\text { a. } \mathrm{m} \text {. }\end{array}$ & $\begin{array}{l}\text { Mean conc. found at } 12 \\
\text { a. } \mathrm{m} \text {. }\end{array}$ & $\begin{array}{l}\text { Mean conc. found at } 2 \\
\text { p. } m \text {. }\end{array}$ & Mean* & SD* & \% RSD* \\
\hline 10 & 9.167 & 9.120 & 9.167 & 9.151 & 0.02673 & 0.29208 \\
\hline 15 & 14.722 & 14.722 & 14.769 & 14.738 & 0.02673 & 0.18137 \\
\hline 20 & 19.815 & 19.861 & 19.722 & 19.799 & 0.07071 & 0.35718 \\
\hline
\end{tabular}

*Average of three concentrations

Table 6: Inter-day precision data and statistical results

\begin{tabular}{|c|c|c|c|c|c|c|}
\hline $\begin{array}{l}\text { Concentration taken } \\
(\mu \mathrm{g} / \mathrm{ml})\end{array}$ & $\begin{array}{l}\text { Mean conc. found on } \\
\text { Day } 1\end{array}$ & $\begin{array}{l}\text { Mean conc. found on } \\
\text { Day } 2\end{array}$ & $\begin{array}{l}\text { Mean conc. found on } \\
\text { Day } 3\end{array}$ & Mean* & SD* & \% RSD* \\
\hline 10 & 9.120 & 9.120 & 9.074 & 9.105 & 0.02673 & 0.29357 \\
\hline 15 & 14.676 & 14.722 & 14.629 & 14.675 & 0.04629 & 0.31546 \\
\hline 20 & 19.769 & 19.769 & 19.722 & 19.753 & 0.02673 & 0.135316 \\
\hline
\end{tabular}

*Average of three concentrations

\section{Repeatability}

The \% RSD was found to be 0.24 as shown in table 7 . The repeatability results of six determinations with same concentration are found to be within limits. Repeatability plays very crucial role in the analysis of drug in bulk as well as in formulations. The results obtained from the repeatability study proved that there was no significant change observed on repetition of methodology. The \% RSD observed was 0.24 and the acceptance criterion is $2 \%$.

Table 7: Results showing repeatability studies

\begin{tabular}{lll}
\hline S. No. & Concentration taken $(\boldsymbol{\mu g} / \mathbf{m l})$ & Conc. found $(\boldsymbol{\mu g} / \mathbf{m l})$ \\
\hline 1. & 20 & 19.861 \\
2. & 20 & 19.769 \\
3. & 20 & 19.769 \\
4. & 20 & 19.861 \\
5. & 20 & 19.861 \\
6. & 20 & 19.861 \\
& Mean* & 19.830 \\
& SD & 0.04781 \\
\hline
\end{tabular}

*Average of six determinations

\section{Ruggedness}

The result was indicated as \% RSD. The results of two analysts with HQ of same concentrations with 6 determinants was shown within limits and Acceptance criteria is $2 \%$. This parameter helps in confirming that no significant change in reliability and repeatability of methodology was observed with the change of analyst. The \% RSD was found to be 0.14 as shown in table 8 .

Table 8: Results indicating ruggedness study

\begin{tabular}{lll}
\hline Concentration taken $(\boldsymbol{\mu g} / \mathbf{m l})$ & Conc. found by analyst $\mathbf{1}(\boldsymbol{\mu g} / \mathbf{m l})$ & Conc. found by analyst $\mathbf{2}(\boldsymbol{\mu g} / \mathbf{m l})$ \\
\hline 20 & 19.861 & 21.329 \\
20 & 19.814 & 21.279 \\
20 & 19.814 & 21.378 \\
20 & 19.861 & 21.329 \\
20 & 19.861 & 21.329 \\
20 & 19.861 & 21.329 \\
Mean* & 19.846 & 21.329 \\
SD & 0.02391 & 0.03137 \\
\% RSD & 0.12047 & 0.14708 \\
\hline
\end{tabular}

*Average of six determinations

\section{Robustness}

The respective absorbances were noted and the result was indicated as \% RSD. The results were obtained at two different wavelengths. Linearity in the results was obtained at specific wavelengths with \% RSD was found to be almost similar. No significant variation was observed in the absorbance of samples. Therefore, the proposed method was considered as robust. The Acceptance Criteria is $2 \%$, hence the results obtained were within the range. 
Table 9: Results showing robustness study

\begin{tabular}{lll}
\hline Concentration taken $(\boldsymbol{\mu g} / \mathbf{m l})$ & Conc. found at 287.6 nm & Conc. found at 291.6 $\mathbf{~ n m}$ \\
\hline 20 & 20.556 & 18.287 \\
20 & 20.707 & 18.194 \\
20 & 20.601 & 18.241 \\
20 & 20.509 & 18.241 \\
20 & 20.509 & 18.241 \\
20 & 20.556 & 18.241 \\
Mean* & 20.548 & 18.241 \\
SD & 0.03485 & 0.02928 \\
\% RSD & 0.16961 & 0.16052 \\
\hline
\end{tabular}

*Average of six determinations

\section{Assay}

The assay for marketed as well as for HQ-loaded NLC formulation having concentration $10(\mu \mathrm{g} / \mathrm{ml})$ is shown in table 4 . The \% age drug recovery was calculated from absorbance value. The validity of the current method was confirmed as validated as the \% age drug recovery was observed to be $90.43 \%$ in case of marketed dosage form of HQ while it was observed to be $91.51 \%$ in prepared NLC formulation.

\section{Degradation studies}

The result of stability studies conducted under different degradation conditions. Percentage degradation was calculated by the formula as given below and percentage recovery was also calculated in each case as shown in table 10.

Degradation $(\%)=\quad \frac{\text { Expected Concentration-Actual concentration) }}{\text { Expected concentration }} \times 100$

Table 4: Assay of marketed and prepared NLC formulation of HQ

\begin{tabular}{llcrr}
\hline Formulation & Amount taken* $(\boldsymbol{\mu g} / \mathbf{m l})$ & Amount recovered & SD* & $\begin{array}{l}\text { \% drug } \\
\text { recovered* } \text { SDD }^{*}\end{array}$ \\
\hline Melalite ${ }^{\circledR}$ Forte Cream 4\% USP & 10 & 9.043 & 0.00116 & $90.43 \pm 0.001$ \\
Hydroquinone-loaded NLC formulation & 10 & 9.151 & 0.591144 \\
\hline
\end{tabular}

${ }^{*}$ mean of three values

Table 10: Table depicting degradation and stability studies

\begin{tabular}{|c|c|c|c|c|}
\hline Parameters studied & Conc. taken $(\mu \mathrm{g} / \mathrm{ml})$ & Conc. found $(\mu \mathrm{g} / \mathrm{ml})$ & \% degradation* & \% recovery* \\
\hline Acid Hydrolysis & 20 & 14.769 & 26.16 & $73.84 \%$ \\
\hline Alkaline Hydrolysis & 20 & 18.935 & 5.32 & $94.68 \%$ \\
\hline Oxidative degradation & 20 & 13.796 & 31.02 & $68.98 \%$ \\
\hline UV degradation & 20 & 19.814 & 0.93 & $99.07 \%$ \\
\hline Thermal degradation & 20 & 19.861 & 0.69 & $99.31 \%$ \\
\hline
\end{tabular}

*Average of three concentrations

The results revealed no change in absorbance of drug solution on UV and thermal degradation as the $\%$ recovery is very close to $100 \%$ which indicates good stability while slight degradation was observed on alkaline hydrolysis. But there was significant change observed with the drug was subjected to acid hydrolysis and (\% degradation of 26.16) and oxidative degradation (\% degradation of $31.02 \%$ ) confirming that HQ is prone to oxidation as well as acid hydrolysis.

Table 11: Table indicating the linearity data of developed method

\begin{tabular}{ll}
\hline Parameters & Values \\
\hline$\lambda$ max $(\mathrm{nm})$ & 289.6 \\
Linearity range $(\mu \mathrm{g} / \mathrm{ml})$ & $5-40$ \\
$\mathrm{LOD}(\mu \mathrm{g} / \mathrm{ml})$ & 0.3161 \\
$\mathrm{LOQ}(\mu \mathrm{g} / \mathrm{ml})$ & 0.9578 \\
Standard Regression Equation & $\mathrm{y}=0.0216 \mathrm{x}$ \\
Slope $(\mathrm{m})$ & 0.0216 \\
Y-intercept $(\mathrm{c})$ & 0 \\
Correlation Co-efficient $\left(\mathrm{R}^{2}\right)$ & 0.998 \\
\% RSD Intra-day(n=3) & 14.56 \\
$\%$ RSD Inter-day(n=3) & 14.5113 \\
$\%$ Recovery & 100.05 \\
\hline
\end{tabular}

\section{CONCLUSION}

HQ was subjected to various studies as per ICH guidelines. It was found that $\mathrm{HQ}$ undergoes significant degradation under acid hydrolysis and is highly prone to oxidation which generally due to its conversion to benzoquinone, whereas it is stable under alkaline UV and thermal treatment. The proposed method was validated for linearity, accuracy, precision, ruggedness and robustness. The method was also applied to marketed as well as prepared NLC formulation and results were statistically compared with reference 
method which showed that there were no significant changes in the result. So, the method can be utilized for determination of the purity of drug available from various sources without any tedious procedure and also used in the analysis of stability study samples.

\section{ACKNOWLEDGMENT}

The authors are grateful to the Rayat Bahra Institute of Pharmacy, Hoshiarpur, India, for giving permission to carry out their research work.

\section{CONFLICT OF INTERESTS}

The authors declare that there is no conflict of interests regarding the publication of this paper.

\section{REFERENCES}

1. Jow, Tiffany J, Hantash, Basil M. Hydroquinone-induced depigmentation: case report and review of the literature. Dermatitis 2014;25:1-5.

2. TseTW. Hydroquinone for skin lightening: safety profile, duration of use and when should we stop? J Dermatolog Treat 2010;21:272-5.

3. Yayli S. Treatment of hyperpigmentation in darker skins. J Pigment Disord 2015;1:158-9.

4. Nordlund JJ. Hyperpigmentation: its historical treatment and the development of hydroquinone. J Pigment Disord 2015;2:221.

5. Palumbo A, d'Ischia M, Misuraca G, Prota G. Mechanism of inhibition of melanogenesis by hydroquinone. Biochim Biophys Acta 1991;1073:85-90.

6. Verma DD, Verma S, Blume G, Fahr A. Liposomes increase skin penetration of entrapped and non-entrapped hydrophilic substances into human skin: a skin penetration and confocal laser scanning microscopy study. Eur J Pharm Biopharm 2003;55:271-7.

7. Shatalebi MA, Mostafavi SA, Moghaddas A. Niosome as a drug carrier for topical delivery of $\mathrm{N}$-acetyl glucosamine. Res Pharm Sci 2010;5:107-17.

8. Schlupp P, Blaschke T, Kramer KD, Holtje HD. Drug release and skin penetration from solid lipid nanoparticles and a base cream: a systematic approach from a comparison of three glucocorticoids. Skin Pharmacol Physiol 2011;24:199-209.

9. Babaei S, Ghanbarzadeh S, Adib ZM, Kouhsoltani M. Enhanced skin penetration of lidocaine through encapsulation into nanoliposomes and nanostructured lipid carriers: a comparative study. Pharmazie 2016;71:247-51.

10. Jain N, Jain R, Banweer J. Development and validation of a rapid RP-HPLC method for the determination of amlodipine besylate and olmesartan medoxomil in their combined tablet formulation. Int J Curr Pharm Res 2010;2:40-3.

11. Siddique S, Parveen Z, Ali Z, Zaheer M. Qualitative and quantitative estimation of hydroquinone in skin whitening cosmetics. J Cosmetis Dermatological Sci Appl 2012;2:224-8.

12. Seokmin J, Yongseong K. Analysis of hydroquinone and its ether derivatives by using micellar electrokinetic chromatography (MEKC). Bull Korean Chem Soc 2005;26:819-22.

13. Desiderio C, Ossicini L, Fanali S. Analysis of hydroquinone and some of its ethers by using capillary electrochromatography. J Chromatogr A 2000;887:489-96.

14. Khoshneviszadeh R, Bazzaz BSF, Housaindokht MR, EbrahimHabibi $A$, Rajabi O. UV spectrophotometric determination and validation of hydroquinone in liposome. Iranian J Pharm Res 2015;14:473-8.

15. Jogarami R, Jain P, Sharma S. Validated UV spectrophotometric method development for simultaneous estimation of tazarotene and hydroquinone in gel preparation. J Pharm Res 2012;5:2273-5.

16. Ghanbarzadeh S, Hariri R, Kouhsoltani M, Shokri J, Javadzadeh Y, Hamishehkar H. Enhanced stability and dermal delivery of hydroquinone using solidlipid nanoparticles. Colloids Surf B 2015;136:1004-10.

17. Barry BW. Mode of action of penetration enhancers in human skin. J Controlled Release 1987;6:85-97.

18. Rathod $\mathrm{BH}$, Rani SS, Kartheek N, Kumar A. UV spectrophotometric method development and validation for the quantitative estimation of indinavir sulphate in capsules. Int J Pharm Pharm Sci 2014;6:598-601.

19. Yasmeen Z, Mamatha T, Farheen H. Dissolution method development and validation for a combination of ibuprofen and paracetamol tablets. Asian J Pharm Clin Res 2013;6:164-8.

20. Khanchandani SS, Galgatte UC, Chaudhari PD. Development and validation of a UV-visible spectroscopic method for estimation of rizatriptan benzoate in bulk and tablet dosage form. Asian J Pharm Clin Res 2013;6:113-6.

21. Moharana AK, Banerjee M, Panda S, Mudali JN. Development and validation of UV spectrophotometric method for the determination of mesalamine in bulk and tablet formulation. Int J Pharm Pharm Sci 2011;3:19-21.

22. Nazemiyeh E, Eskandani M, Sheikhloie $H$, Nazemiyeh $H$. Formulation and physicochemical characterization of lycopene-loaded solid lipid nanoparticles. Adv Pharm Bull 2016;6:235-41.

23. Sisinthy SP, Duraipandi S, Rao NK, Rao MB. Determination and validation of HPLC with UV-detection of Itopride hydrochloride in human serum. Int J Pharm Pharm Sci 2015;7:246-9.

24. Sheliya K, Shah K, Kapupara P. Development and validation of analytical method for simultaneous estimation of mometasone furoate, hydroquinone and tretinoin in the topical formulation by RP-HPLC. J Chem Pharm Res 2014;6:934-40.

25. Kipngetich TE, Hillary M, Shadrack M. UV-Vis analysis and determination of hydroquinone in body lotions and creams sold in retail outlets in baraton, Kenya. Baraton Interdisciplinary Res J 2013;3:23-8.

26. Beckett AH, Stenlake JB. Practical pharmaceutical chemistry. 4th ed. Part 2. New Delhi: CBS Publishers and distributors; 1997.

27. Kumar BK, Thiruvengadarajan VS, Begum NT. Analytical method development and validation of lidocaine in ointment formulation by the UV-spectrophotometric method. Int J Pharm Pharm Sci 2012;4:610-4.

28. Balasaheb BG, Balasaheb AK, Subhash TR, Jijabapu K, Sudhakar PS. Development and validation of a UV-spectrophotometric method for estimation of dolutegravirsodium in tablet dosage form. Malaysian J Anal Sci 2015;19:67-78.

29. Joana G, Zelia B. Validation of two spectrophotometric methods for fluoxetine quantification. Int J Pharm Pharm Sci 2016;8:72-8.

30. Jain PS, Chaudhari AJ, Patel SA, Patel ZN, Patel DT. Development and validation of the UV spectrophotometric method for determination of terbinafine hydrochloride in bulk and in the formulation. Pharm Methods 2011;2:89-95.

31. Sharma K, Agarwal SS, Gupta M. Development and validation of a UV-spectrophotometric method for estimation of curcumin in bulk drug and pharmaceutical dosage forms. Int J Drug Dev Res 2012;4:375-80.

32. Ethiraj R, Thiruvengadam E, Sampath VS, Vahid A, Raj J. Development and validation of stability indicating a spectroscopic method for content analysis of ceftriaxone sodium in pharmaceuticals. Int Scholarly Res Not 2014. http://dx.doi.org/10.1155/2014/278173

33. ICH, Q2 (R1) Validation of analytical procedure, text and methodology. International Conference on Harmonization; 2016.

\section{How to cite this article}

- $\quad$ Sukhjinder Kaur, Taranjit Kaur, Gurdeep Kaur, Shivani Verma. Development and validation of a UV-spectrophotometric method for estimation of hydroquinone in bulk marketed cream and prepared NLC formulation. Int J Appl Pharm 2017;9(5):102-108. 